\title{
SDU\%
}

\section{Mutual Recognition for Sale: \\ International Bargaining over Product Standards}

by

Dapeng Cai and Jan Guldager Jørgensen

Discussion Papers on Business and Economics

No. $1 / 2017$

FURTHER INFORMATION

Department of Business and Economics

Faculty of Business and Social Sciences

University of Southern Denmark

Campusvej 55, DK-5230 Odense M

Denmark 


\title{
Mutual Recognition for Sale: International Bargaining over Product Standards
}

\author{
Dapeng Cai*, Jan Guldager Jørgensen** \\ * Nanzan University, Japan, e-mail: dcai@nanzan-u.ac.jp; \\ ** Corresponding author: University of Southern Denmark, Department of Business and Economics, \\ Campusvej 55, DK-5230 Odense M, Denmark, e-mail: jgj@sam.sdu.dk
}

\begin{abstract}
We model a two-country bargaining process over the coordination of a horizontally differentiated product standard. We show that the necessary conditions for bargaining to take place are (i) firm heterogeneity and (ii) sufficiently high complying costs. When firms compete à la Cournot in the Home market and when bargaining takes place, our results suggest that mutual recognition of standards, and not the harmonization of standards, inevitably emerges as Home's optimal choice. We also demonstrate that mutual recognition can maximize global welfare. Our results largely hold when firms compete à la Bertrand.
\end{abstract}

Keywords: Product standards; Mutual recognition; Harmonization; International bargaining; Lobbying; Horizontal differentiation

JEL classification codes: C71, F12, F13, D72 


\section{Introduction}

Non-tariff measures (NTMs), such as product standards and regulations, are increasingly being used as instruments to shield domestic markets from foreign competition. ${ }^{1}$ A prototype example would be the different technical standards concerning the seat belt anchoring that have been introduced in the EU and the United States. Although all investigations demonstrate that these standards lead to an equivalent high level of safety for the passengers in the car (i.e., technically there are no differences (EU Commission 2015)), all cars sold would have to comply with the local safety standards, which cost substantial amounts of time and money.

Given the potential protectionist nature of NTMs, it is only natural to see that demands for international coordination of the NTMs have recently come to dominate the free trade talks. ${ }^{2}$ Whether and how countries would choose to coordinate their NTMs through negotiation merits careful consideration. Nevertheless, despite a growing literature on NTMs that dates from Nelson (1970) and Darby and Karni (1973), and an extensive literature on the

\footnotetext{
${ }^{1}$ Empirical work confirms that NTMs create substantial costs for firms, constituting far larger barriers to trade than the remaining tariffs (see, e.g., Chen 2004; Anderson and van Wincoop 2004; WTO 2005; 2012). Pelkmans (2015) shows that the tariff equivalence of some NTMs can be as high as 15-72\%.

${ }^{2}$ Coordination of NTMs was an important issue in the EU-Canada trade negotiations, which led to the Comprehensive Trade and Economic Agreement (CETA), as well as in the negotiations concerning the Trans-Pacific Partnership (TTP) and the Transatlantic Trade and Investment Partnership (TTIP).
} 
political economy of policy formation that stems from the seminal paper of Grossman and Helpman (1994), this important issue has not been formally analyzed. ${ }^{3}$

The present paper tries to close this gap by casting the analysis in a political and international economy setup. We construct a simple game theoretical model that explicitly examines the international bargaining process behind the coordination of a product standard. The standard we consider is horizontally differentiated: At one end of the scale of degrees of coordination of standards we have the principle of mutual recognition, and at the other end we have the principle of harmonization. ${ }^{4}$ If a standard is approved in one country under mutual recognition, then the standard is also accepted in all participating countries; hence, all firms are allowed to sell on all markets. Harmonization, on the other hand, requires that the participating countries agree to let one standard serve as the common standard; hence, while previous national standards may still prevail on the domestic market, firms can only trade with other countries if they live up to the common standard.

We construct a model with two countries, Home and Foreign, with a firm producing a good in each country. The Home government considers whether to introduce a new product standard on the imported goods sold in the Home market, which can differ from the one imposed on the Home firm's products. In prescribing the new standard, the Home government is effectively banning imports of goods that fail to meet the standard. However, complying with the adopted standard is assumed to be costly. Because of the presence of

\footnotetext{
${ }^{3}$ An excellent survey of the literature on standards and political economy can be found in Swinnen et al. (2015).

${ }^{4}$ See Pelkmans (2012) for an analysis of mutual recognition and harmonization in the EU.
} 
complying costs, we see that Foreign has an incentive to provide an impetus to induce Home to adopt a more favorable standard, so as to reduce its complying costs.

As for results, we first show that the necessary conditions for the two-country bargaining to take place are (i) firm heterogeneity and (ii) sufficiently high complying costs. We then show that when firms compete à la Cournot in the Home market and when bargaining takes place, mutual recognition of standards, and not the harmonization of standards, inevitably emerges as the Home government's optimal choice. Our argument is that this happens primarily because when bargaining occurs, the bargaining process induces the Home government to maximize the profits of foreign firms. In addition, we also demonstrate that mutual recognition can in fact maximize global welfare. We then show that our results largely hold when firms compete à la Bertrand. They are also robust under the case of an endogenously determined tariff rate.

Our findings thus predict that when it comes to horizontally differentiated standards, not only does harmonization hardly ever emerge as a possible outcome of the international negotiations of the product standards, but pursuing it may in fact worsen domestic welfare. We believe that this new insight is relevant to the debate on the necessity of the international coordination of product standards that has recently arisen in the international trade negotiations. 
Our paper contributes to an emerging literature that investigates the theoretical foundations for, as well as the empirical aspects of, product standards. ${ }^{5}$ Recently, a growing number of theoretical works have begun to apply the seminal "protection for sale" framework of Grossman and Helpman (1994) to a standard setting. ${ }^{6}$ Clearly, this is because the introduction of standards typically impacts the interests of different groups, and these groups are thus induced to lobby to influence government decisions on standards. Important recent contributions include that of Swinnen et al. (2015), who develop a political economy model of standards, in which both producers and consumers are actively and simultaneously lobbying under both a closed economy setting and an open economy setting. However, their focus is on vertically differentiated standards, and they aim to examine the possibilities of "overstandardization" and "understandardization." Moreover, they assume that firms have identical interests in the standards and that there exists no strategic interactions among firms. Closely related to our work is Jørgensen and Schröder (2014), who also consider horizontally differentiated standards and firms' strategic interactions. Their results also confirm that

\footnotetext{
5 Theoretical works like Felbermayr and Jung (2011), for example, focus on the heterogeneity of firms and how technical barriers affect firms' productivity. Edwards and Poyago-Theotoky (2013), on the other hand, link R\&D cooperation and product standards and show how standards can exclude foreign firms from the domestic market. Empirical work on the international coordination of standards includes Orefice et al. (2012), Orefice and Rocha (2014), and Togan (2015). Chen and Mattoo (2008) and Orefice et al. (2012) also find substantial differences in the trade effects of these two schemes, mutual recognition and harmonization.

${ }^{6}$ Related work also includes Limao and Tovar (2011), who link NTMs, political economy, and special interest groups, and Sturm (2006), who investigates the emergence of protective standards.
} 
mutual recognition is the most robust in generating trade and in avoiding potential welfare losses. However, they consider the case where industries lobby to influence the decision about the coordination regime (mutual recognition or harmonization) that is taken by a supranational body, such as the European Commission. Moreover, the international bargaining process has not been explicitly considered in their analysis. Hence, the research questions that we aim to answer in this paper, namely how the choice of standards in the domestic country can be influenced by side payments from a foreign country and how side payments are endogenously determined in the negotiation process, still remain unanswered despite their importance.

The remainder of the paper is organized as follows. Section 2 presents the basic model and derives the Nash equilibrium in the absence of side payments. It then examines Home-Foreign bargaining, where Foreign compensates Home for its changes in standards with a side payment. In Section 3, we discuss the robustness of the main results by extending the model to the case where the tariff rate is determined endogenously. Section 4 then concludes.

\section{The basic model}

There are two countries, Home and Foreign (denoted by superscripts $h$ and $f$, respectively), with one firm residing in each country comprising the $\mathrm{H}$ firm and the $\mathrm{F}$ firm, respectively. Both firms produce a product for the Home market, with potentially different product 
standards. However, consumers are assumed to lack the relevant information and are not able to distinguish the differences in the goods produced under different standards. They thus treat the products of the two firms as the same homogenous product.

The products of the $\mathrm{H}$ firm are assumed to have met a product standard set by the Home government. The Home government now considers introducing a new product standard on imported goods sold in the Home market, which can differ from the one already imposed on the H firm's products. In prescribing the new standard, the Home government is effectively banning imports of goods that fail to meet the standard. In other words, if the F firm wants to export to the Home market, it will have to comply with Home's new standard. We assume that it is costly to comply, and in order to comply the F firm must incur an additional cost.

The new product standard to be determined by the Home country is horizontally differentiated. Let $\delta \in[0,1]$ denote the level of the standard. Without loss of generality, we assume that initially the standard adopted in Home and by the $\mathrm{H}$ firm corresponds to $\delta=1$, whereas the one adopted by the F firm in Foreign corresponds to $\delta=0$. Let $e(\geq 0)$ be the unit cost for the F firm to comply with the new standard. Accordingly, if the Home government sets the standard at $\delta$, the complying cost of the $\mathrm{F}$ firm would be $\delta e$. The situations of mutual recognition and harmonization of standards are encompassed by the scope of $\delta$. Clearly, when $\delta=0$, Home chooses to simply recognize the standard originally applied to the products of the F firm (the case of mutual recognition), and the complying cost for the F firm would be zero. In contrast, when $\delta=1$, Home chooses to adopt the standard 
initially applied for the $\mathrm{H}$ firm (the case of harmonization), and the complying cost for the $\mathrm{F}$ firm would be $e$.

The inverse demand function in the Home country is given by $p=a-q^{h}-q^{f}$, where $a(>0)$ represents the size of the Home market, $q^{h}$ is the $\mathrm{H}$ firm's output, and $q^{f}$ is the imports from the F firm. For tractability and without loss of generality, we assume that the $\mathrm{H}$ firm's marginal production cost is a constant, $c(\geq 0)$, whereas that of the $\mathrm{F}$ firm is given by zero. The two firms' profits in the Home market are given by:

$$
\begin{gathered}
\pi^{h} \equiv(a-q) q^{h}-c q^{h}, \\
\pi^{f} \equiv(a-q-\delta e-t) q^{f},
\end{gathered}
$$

where $q=q^{n}+q^{f}$, and $t(\geq 0)$ is Home's exogenously given tariff rate. From (2) we see that because it is costly to comply with the new product standard, the F firm has no incentive to voluntarily adopt a standard that is higher in value than $\delta$. We also assume that the $\mathrm{F}$ firm chooses to export to the Home market if and only if its profits $\pi^{f}$ are nonnegative (i.e., $\left.\pi^{f} \geq 0\right)$

The social welfare of Home, $W^{h}$, is given by:

$$
W^{h}=\pi^{h}+C S^{h}+t q^{f},
$$

where $C S^{h} \equiv q^{2} / 2$ is Home's consumer surplus, and $t q^{f}$ is the tariff revenue. 
The Home government is assumed to have a broader objective function, compared with that of the social planner. Following Grossman and Helpman (1994), we assume that the Home government cares about social welfare as well as the possible side payments from Foreign, $S(\geq 0)$. The Home government values the side payments from Foreign because (i) they are net transfers of foreign assets into the Home and thus can increase the Home's national income (Cai and $\mathrm{Li} 2014$ ); (ii) they enter directly into the coffer of the Home government, with which the Home government enjoys greater discretion compared with domestic surplus (Konishi et al. 1999), (iii) they can help the Home government survive the politically and economically costly adjustments that accompany the adoption of new policies (Baccini and Urpelainen 2012), and (iv) due to the excess burden of taxation, it can be more costly to raise the same amount of funds from the profit of the $\mathrm{H}$ firm via taxation. Accordingly, we assume that the Home government values a dollar in the form of a side payment from Foreign as a dollar in Home, and its objective function is the sum of social welfare, $W^{h}$, and the side payments from the Foreign government, $S$ :

$$
G^{h}=W^{h}+S .^{7}
$$

\footnotetext{
${ }^{7}$ As demonstrated in Stoyanov (2009), some governments assign more weight to pecuniary side payments than to national welfare, and that a relatively small amount of side payments may have substantial policy impacts. Accordingly, a more general form to model the Home government's objective would be $G^{h}=W^{h}+\rho S$, where $\rho \geq 1$ (i.e., the Home government assigns at least as much weight to a dollar in the form of a side payment from Foreign as a dollar in Home). Nevertheless, all our results hold when $\rho \geq 1$.
} 
The Foreign government's objective function is assumed to be the profits of the F firm in the Home market less the side payments to Home, and is given by

$$
G^{f}=\pi^{f}-S
$$

We consider a simple two-stage game. The players are the Home government, the Foreign government, the $\mathrm{H}$ firm, and the $\mathrm{F}$ firm. ${ }^{8}$ In Stage 1, the two governments bargain over the level of Home's new standard and the amount of side payments from Foreign to Home. When bargaining fails, the Home government is assumed to choose the optimal standard that maximizes Home's social welfare. In Stage 2, firms compete in the Home market. We analyze the market equilibria under both Cournot and Bertrand competition. We employ backward induction to solve this game.

\subsection{Cournot competition}

We first examine the case of Cournot competition and start by analyzing Stage 2 .

\footnotetext{
${ }^{8}$ To focus on the political interactions between the conflicting firms, we here ignore the possibility that consumers can also influence the setting of standards. This can be justified, for example when the associated information costs for the consumers to understand the impacts of the standards are prohibitively high, which prevent them from participating in the political process. See Swinnen et al. (2015) for a political economy model of standards in which the lobbies include both producers and consumers.
} 


\subsubsection{Output}

In Stage 2, the two firms simultaneously decide their outputs to maximize their respective profits, $\pi^{i}(i=h, f)$. To ensure that both firms have positive outputs, we assume that Home's market size is sufficiently large (i.e., $a>2 e+2 c-t$ ). The firms' optimal outputs are

$$
q^{h}=(a-2 c+\delta e+t) / 3, q^{f}=[a+c-2(\delta e+t)] / 3 .
$$

The corresponding profits are accordingly given by

$$
\pi^{h}=(a-2 c+\delta e+t)^{2} / 9, \pi^{f}=[a+c-2(\delta e+t)]^{2} / 9 .
$$

Clearly, the $\mathrm{F}$ firm chooses to export to the Home market even when $\delta=1$ because $\left.\pi^{f}\right|_{\delta=1}>0$, i.e., it is profitable for the $\mathrm{F}$ firm to export to the Home market even when the Home government harmonizes the standard. Put otherwise, the F firm's cost of implementing the new standard is not prohibitively high. ${ }^{9}$

\subsubsection{The socially optimal standard}

\footnotetext{
${ }^{9}$ The case of prohibitively high complying costs for implementing new standards has been examined in, for example, Jørgensen and Schröder (2014).
} 
As a benchmark, we consider the socially optimal standard chosen by the Home's social planner, who maximizes social welfare given by (3). Substituting (6) and (7) into (3), we see that social welfare is given by

$$
W^{h}=\left[2 a^{2}+3 c^{2}-2 c \delta e+2 a(t-2 c)+(\delta e-3 t)(\delta e-t)\right] / 6 .
$$

Twice differentiating $W^{h}$ with respect to $\delta$ gives $\partial^{2} W^{h} / \partial \delta^{2}=e^{2} / 3>0$. Obviously, $W^{h}(\delta)$ is a strictly convex function of $\delta$, with the optimal standard being obtained at the endpoints of the domain of $\delta$ (i.e., either $\delta^{0}=0$ or $\left.\delta^{0}=1\right) .{ }^{10}$ We note that

$$
\left.W^{h}\right|_{\delta=0}-\left.W^{h}\right|_{\delta=1}=\frac{e}{6}(2 t+2 c-e)
$$

Together with the positive outputs assumption, we see that $\left.W^{h}\right|_{\delta=0} \geq\left. W^{h}\right|_{\delta=1}$ when $e \leq 2 c+2 t$, and $\left.W^{h}\right|_{\delta=1}>\left.W^{h}\right|_{\delta=0}$ when $2 c+2 t<e<\frac{1}{2}(a+c-2 t)$. We then summarize the above discussion as the following proposition.

Proposition 1. In the absence of bargaining, the social planner in Home chooses to mutually recognize product standards (i.e., $\delta^{0}=0$ ) when the complying cost is sufficiently low (i.e., $e \leq 2 c+2 t$ ). Conversely, when the complying cost is sufficiently high (i.e., $2 c+2 t<e<\frac{1}{2}(a+c-2 t)$, it chooses to harmonize the standard (i.e., $\left.\delta^{0}=1\right)$.

\footnotetext{
${ }^{10}$ We use the superscript 0 to denote the social optimum.
} 
The intuition underlying Proposition 1 is simple. To maximize social welfare, the social planner would manipulate the standard to make the cost differential between the two firms as large as possible, because this move would induce the more efficient firm to maximize its output. This explains why the social planner's choice would only be polar cases, either mutual recognition or harmonization, irrespective of the continuum of standards available. Put differently, in an effort to maximize social welfare, the social planner is using the choice of standard as a strategic tool to discipline the less efficient firm and to favor the more efficient firm: When the complying cost is sufficiently high (suggesting that the F firm can be sufficiently inefficient), it chooses to help the $\mathrm{H}$ firm while biasing against the $\mathrm{F}$ firm. Conversely, when the complying cost is sufficiently low (suggesting that the F firm can be sufficiently efficient), it chooses to help the $\mathrm{F}$ firm while hurting the $\mathrm{H}$ firm, thus increasing the consumer surplus and the tariff income, although doing so reduces producer surplus.

From (9) we note that when $c=e$, we have $\left.W^{h}\right|_{\delta=0}>\left.W^{h}\right|_{\delta=1}$, which indicates that $\delta^{0}=0$. We then note as follows:

Corollary 1. When the marginal production cost of the domestic firm equals the complying cost of the foreign firm under the harmonized standard (i.e., $c=e$ ), the social planner chooses mutual recognition (i.e., $\left.\delta^{0}=0\right)$.

Corollary 1 suggests that bargaining never takes place when firms have identical constant marginal costs under the case of harmonization. Moreover, following Proposition 1, we immediately note the following: 
Corollary 2. Bargaining between the two governments occurs only when the complying cost is sufficiently high (i.e., $\left.2 c+2 t<e<\frac{1}{2}(a+c-2 t)\right)$.

Corollaries 1-2 together suggest two necessary conditions for bargaining to occur: (i) Firm heterogeneity (i.e., when the production cost of the domestic firm differs from the complying cost of the foreign firm under the case of harmonization) and (ii) sufficiently high complying costs. Put otherwise, bargaining occurs only when firms are strongly asymmetric. In the literature on international environmental agreements (IEAs), it has also been reported that when countries are strongly asymmetric, allowing side payments can produce self-enforcing cooperative agreements between countries, for strong asymmetry 'ratchets up' the cooperation problem from being one of supplying the public good to being one of paying others to supply the good (Barrett 2003). In the ensuing analyses, we will examine the outcome of such a bargaining process when it occurs.

\subsubsection{Equilibrium standard as an outcome of bargaining}

We now turn to stage 1 and model the intergovernmental negotiation process between Home and Foreign as a Nash bargaining problem, in which the Home and the Foreign governments have bargaining powers of $\alpha(\in[0,1])$ and $1-\alpha$, respectively. Both parties bargain simultaneously over Home's new product standard, $\delta$, along with the magnitude of a side 
payment, $S$. When $2 c+2 t<e<\frac{1}{2}(a+c-2 t)$, anticipating that $\delta^{0}=1$ will be chosen by Home when bargaining breaks down, Foreign provides no side payments unless $\delta<\delta^{0}$. The threat point is assumed to be the status quo, where Foreign makes no side payments and Home chooses $\delta^{0}$. Letting $\Delta W^{h}$ (respectively, $\Delta \pi^{f}$ ) denote the change of $W^{h}$ (respectively, $\pi^{f}$ ) when the standard decreases from $\delta^{0}$ to $\delta$, then for $\delta<\delta^{0}$, the Nash bargaining solution solves the following maximization problem:

$$
\max _{\delta, S}\left[\Delta W^{h}+S\right]^{\alpha}\left[\Delta \pi^{f}-S\right]^{1-\alpha}
$$

which is equivalent to $\max _{\delta, S} \alpha \ln \left[\Delta W^{h}+S\right]+(1-\alpha) \ln \left[\Delta \pi^{f}-S\right]$.

As in Maggi and Rodríguez-Clare (1998), the outcome of the bargaining process, $\left(\delta^{*}, S^{*}\right)$, satisfies the following two conditions. ${ }^{11}$

(i) The term $\delta^{*}$ maximizes the joint surplus of the two governments, $J S(\delta) \equiv \Delta W^{h}+\Delta \pi^{f} .{ }^{12}$ It is easy to verify that $\partial^{2}\left(\Delta W^{h}+\Delta \pi^{f}\right) / \partial \delta^{2}=11 e^{2} / 9>0$. Therefore, $J S(\delta)$ is a strictly

${ }^{11}$ We use the superscript $*$ to represent the equilibrium of the bargaining problem.

${ }^{12}$ For bargaining to occur, both parties must benefit from doing so (i.e., $\Delta \pi^{f}-S>0$ and $\Delta W^{h}+S>0$, or $\left.\Delta \pi^{f}+\Delta W^{h}>0\right)$. The objective of the Foreign government is: $\max _{\delta, S} \Delta \pi^{f}-S$, subject to $\Delta W^{h}+S>0$, which can be restated as $\max _{\delta, S} \Delta \pi^{f}+\Delta W^{h}$. Likewise, the Home government's objective can also be restated as $\max _{\delta, S} \Delta W^{h}+\Delta \pi^{f}$ 
convex function of $\delta$. Thus, the equilibrium standard is obtained at the endpoints of the domain of $\delta$. We then have

$$
\Omega \equiv J S(0)-J S(1)=J S(0)=\frac{e}{18}(8 a-11 e+14 c-10 t)
$$

Clearly, $\Omega>0$ when $2 c+2 t<e<\frac{1}{2}(a+c-2 t)$. Hence, when bargaining takes place, we have $\delta^{*}=0$.

(ii) The term $S$ is a weighted average of the welfare loss of Home from the changes in standards and the changes in the welfare of Foreign because

$$
S^{*}=-(1-\alpha) \Delta W^{h}+\alpha \Delta \pi^{f}
$$

Note that when $\alpha=0$ (i.e., Home has no bargaining power), the side payments from Foreign exactly compensates Home for its welfare loss. On the other hand, if $\alpha=1$, Home extracts the entire surplus derived by the $\mathrm{F}$ firm from the changes in standards, which equals $\Delta \pi^{f}$. It is also easy to show that when bargaining takes place, the side payment is positive (i.e., $\left.\left.S^{*}\right|_{\delta^{*}=0}>0\right) .{ }^{13}$ We can summarize the above discussion as the following proposition.

Proposition 2. When bargaining occurs (i.e., $2 c+2 t<e<\frac{1}{2}(a+c-2 t)$ ), the Home government chooses mutual recognition (i.e., $\delta^{*}=0$ ).

${ }^{13}$ Clearly, $\left.S^{*}\right|_{\delta^{\prime}=0}=e(8 a \alpha-6 c+14 \alpha c+3 e-11 \alpha e-6 t-10 \alpha t) / 18>0$. 
As suggested by Proposition 1, when the F firm's complying cost is sufficiently high, mutual recognition brings about a cost to Home's social welfare. Bargaining thus functions as a redistribution mechanism through which Foreign may compensate Home for its loss by means of side payments. In the meantime, bargaining also induces both countries to value the joint surplus, a sum of the changes in both countries' welfare, as well as the changes in the F firm's profit. When bargaining occurs, joint surplus would be positive, suggesting that the absolute value of the changes in the F firm's profit dominates that of the changes in both countries' welfare. Apparently, this induces the Home government to maximize the F firm's profit by shifting profits from the $\mathrm{H}$ firm to the $\mathrm{F}$ firm as much as possible. This is achieved by minimizing the complying cost by mutually recognizing the standards.

As demonstrated in Figure 1, Propositions 1 and 2 together suggest that given the possibility of bargaining, mutual recognition of standards, and not the harmonization of standards, inevitably emerges as Home's optimal choice.

(Figure 1 around here.)

\subsection{The Bertrand competition}

We proceed to consider the Bertrand competition case (denoted by superscript $B$ ). Clearly, depending on the firms' marginal costs, $c$ and $\delta e$, there would be two sub-cases: (i) When $c \geq \delta e$, the $\mathrm{F}$ firm acquires the whole market (denoted by subscript $f$ ), and (ii) when $c<\delta e$, the $\mathrm{H}$ firm acquires the whole market (denoted by subscript $h$ ). 


\subsubsection{Case (i) where the F firm acquires the whole market}

First, we analyze Stage 2. When $c \geq \delta e$, both firms charge price $p_{f}^{B}=c$ (the $\mathrm{F}$ firm charges slightly below $c$ to make sure that it has the whole market), with $q_{f}^{B h}=0$ and $q_{f}^{B f}=a-c$. Hence, the $\mathrm{F}$ firm is making a profit, with $\pi_{f}^{B f}=(c-\delta e)(a-c)$, whereas the $\mathrm{H}$ firm is not making any profit, with $\pi_{f}^{B h}=0$. Social welfare is given by $W_{f}^{B h} \equiv C S_{f}^{B h}+t q_{f}^{B f}=(a-c)^{2} / 2+t(a-c)$, which immediately implies the following:

Proposition 3. When $c \geq \delta e$, the social planner would be indifferent toward the level of the standard, $\delta$.

Nevertheless, because $\partial \pi_{f}^{B f} / \partial \delta=-(a-c) e<0$, the $\mathrm{F}$ firm has an incentive to bargain with the policymakers in Home to reduce $\delta$. Next, we proceed to Stage 1 and consider such a bargaining problem. The joint surplus of the two governments is given by

$$
J S_{f}^{B}=\Delta W_{f}^{B h}+\Delta \pi_{f}^{B f}=(a-c)(1-\delta) e .
$$

We then note as follows:

Proposition 4. When $c \geq \delta e$, and if bargaining occurs, the Home government chooses mutual recognition (i.e., $\delta_{f}^{B^{*}}=0$ ). 
Proposition 4 closely resembles Proposition 2, again because that in an effort to maximize the joint surplus, the Home government minimizes the complying cost of the $\mathrm{F}$ firm, which is more efficient when $c \geq \delta e$.

\subsubsection{Case (ii) where the H firm gets the whole market}

When $c<\delta e$, both firms charge price $p_{h}^{B}=\delta e$ (now the $\mathrm{H}$ firm charges slightly below $\delta e$ to make sure that it has the whole market), with $q_{h}^{B h}=a-\delta e$, and $q_{h}^{B f}=0$. Hence, the $\mathrm{H}$ firm is making a profit, with $\pi_{h}^{B h}=(\delta e-c)(a-\delta e)$, whereas the $\mathrm{F}$ firm is not making any profit, with $\pi_{h}^{B f}=0$. Social welfare is given by

$$
W_{h}^{B h} \equiv \pi_{h}^{B h}+C S_{h}^{B h}=(\delta e-c)(a-\delta e)+(a-\delta e)^{2} / 2 .
$$

Because $\partial W_{h}^{B h} / \partial \delta=e(c-\delta e)>0$ and $\partial^{2} W_{h}^{B h} / \partial \delta^{2}=-e^{2}<0$, we see that the social planner sets the optimal standard at $\delta_{h}^{B 0}=c / e<1$. Furthermore, because $\pi_{h}^{B f}=0$, the F firm can only make a contribution of zero, indicating that the Home government shares the Home social planner's objective and would also set $\delta_{h}^{B 0}=\delta_{h}^{B^{*}}=c / e$.

Proposition 5. When $c<\delta e$, the Home social planner and the Home government both set $\delta=c / e$. 
The Home social planner is not choosing harmonization because a small increase in $\delta$ produces a tradeoff: While it increases the H firm's markup, it also decreases its output. Accordingly, the Home social planner (as well as the Home government) would choose to balance these two effects by selecting an interior $\delta$.

\subsection{A remark on the global welfare}

Finally, we consider the impact of the coordination of standards on global welfare. We note that when considering global welfare, the side payments paid by Foreign and those received by Home, as well as the tariff payments and revenues, exactly cancel out. Accordingly, global welfare is defined as the sum of consumer surplus in the Home market, producer surplus of the two firms, and Home's tariff income, and is given by

$$
G W \equiv C S^{h}+\pi^{h}+t q^{f}+S+\pi^{f}-S .
$$

\subsubsection{The case of Cournot competition}

We first consider the case of Cournot competition. Substituting (6) and (7) into (15), we see that $\partial G W / \partial \delta=11 e^{2} / 9>0$, indicating that global welfare is maximized when either $\delta=0$ or $\delta=1$. Together with the assumption that both firms produce positive outputs, it is easy to verify that $\left.G W\right|_{\delta=0}-\left.G W\right|_{\delta=1}=e(8 a+14 c-11 e-10 t) / 18>0$. Hence, we see that mutual recognition always improves global welfare, because requiring the $\mathrm{F}$ firm to comply with the standard can be a costly distortion, and competition is maximized at $\delta=0$. This result 
clearly suggests the strategic potential of bargaining in improving global welfare. Jørgensen and Schröder (2014) also report that mutual recognition is the most robust in generating trade and in preventing potential welfare losses.

\subsubsection{The case of Bertrand competition}

As before, we distinguish between two subcases for the case of Bertrand competition: (i) When $c \geq \delta e$, the $\mathrm{F}$ firm acquires the whole market (denoted by subscript $f$ ), and (ii) when $c<\delta e$, the $\mathrm{H}$ firm acquires the whole market (denoted by subscript $h$ ).

We first consider case (i) where $c \geq \delta e$. Global welfare is given by $G W_{f}^{B}=(a-c)(a+c-\delta e)$. We $\quad$ see $\quad$ that $\quad \partial G W_{f}^{B} / \partial \delta=-e(a-c)<0 \quad$ and $\left.G W_{f}^{B}\right|_{\delta=0}-\left.G W_{f}^{B}\right|_{\delta=1}=(a-c) e>0$. Hence, it is evident that mutual recognition always improves global welfare, again because when $\delta=0$, the distortion generated by the standard is removed, and competition is maximized.

Next, we consider the case (ii) where $c<\delta e$. As stated in Proposition 5, we see from the previous analysis that the Home social planner as well as the Home government both set $\delta_{h}^{B 0}=\delta_{h}^{B *}=c / e$. Global welfare is then given by $G W_{h}^{B}=(a-\delta e)(a-2 c+\delta e) / 2$. Clearly, we see that global welfare is maximized at $\delta=c / e$, since $\left.G W_{h}^{B}\right|_{\delta=c / e}-\left.G W_{h}^{B}\right|_{\delta=0}=c^{2} / 2>0$, and $\left.G W_{h}^{B}\right|_{\delta=c / e}-\left.G W_{h}^{B}\right|_{\delta=1}=(c-e)^{2} / 2>0$. 
Hence, in this case, setting the standard at $\delta=c / e$ leads to a higher level of global welfare, compared with the cases of both mutual recognition and harmonization. Again, while a small increase in $\delta$ increases the $\mathrm{H}$ firm's markup, it also decreases its output, thus necessitating an interior $\delta$ to balance these two effects.

\section{Discussion: The case of an endogenously determined tariff rate}

In this section, we check the robustness of the preceding results. We consider the case in which the tariff rate is endogenously determined when firms compete in the Home market, à la Cournot as well as à la Bertrand. Accordingly, we modify the game structure as follows: In Stage 1, the two governments bargain over the level of Home's new product standard and the magnitude of the side payments. Again, when bargaining fails, the Home government is assumed to maximize its social welfare by choosing the optimal standard. In Stage 2, the Home government sets the tariff rate to maximize its objective (4). ${ }^{14}$ In Stage 3, firms compete in the Home market, either à la Cournot or à la Bertrand. We employ backward induction to solve this game. The remaining specifications are unchanged from the preceding section.

\footnotetext{
${ }^{14}$ The game sequence here clearly is not the unique one. If instead, tariff is endogenously chosen in Stage 1, while the standard is determined in Stage 2, the optimal tariff that maximizes (4) can then be given by $t^{*}=(3 a-(3+5 \alpha) e) / 9$. Note that under such a case, $\pi^{f}=[3 a+9 c+2 e(3+5 \alpha)]^{2} / 729>0$.
} 


\subsection{The case of Cournot competition}

We first consider the case where, the two firms engage in Cournot competition (denoted by superscript $T$ ) in stage 3 . We see that the equilibrium outputs and profits are the same as in (6) and (7), respectively. To ensure positive outputs, we assume that $a>\max \{4 e-3 c, 3 c / 2\}$. Substituting (6) and (7) into (4), differentiating it with respect to $t^{T}$, and then equating it to zero, we derive the optimal tariff rate chosen by the Home government in Stage 2: $t^{T *}=(a-\delta e) / 3>0$. Clearly, because $\partial t^{T *} / \partial \delta=-e / 3<0$, we see that $t^{T *}$ attains its minimum when $\delta=0$.

Substituting $t^{T *}$ back to (7), we see that $\pi^{T f}=(a+3 c-4 \delta e)^{2} / 81$. Because $\partial^{2} \pi^{T f} /\left(\partial \delta^{T}\right)^{2}=(a+3 c)^{2} / 81>0$, we see that the F firm sets either $\delta^{T}=0$ or $\delta^{T}=1$.

Noting that $\left.\pi^{T}\right|_{\delta=0}-\left.\pi^{T}\right|_{\delta=1}=8(a+3 c-2 e) / 81>0$, we see that the F firm sets $\delta^{T}=0$ in the absence of bargaining. Moreover, it is easy to verify that $e-\left(t-\left.t\right|_{\delta=0}\right)=(3+\delta) e / 3>0$ (i.e., to the F-firm, it is "cheaper" to set $\delta^{T}=0$ voluntarily than to be punished by the tariff). Finally, we note that $\left.G^{h T}\right|_{\delta=0}-\left.G^{h T}\right|_{\delta=1}=e(a+3 c-2 e) / 9>0$ (i.e., the Home government always chooses mutual recognition). We can then summarize the above findings as follows:

Proposition 6. When the tariff can be endogenously chosen, the Home government chooses mutual recognition (i.e., $\delta^{T^{*}}=0$ ), and bargaining never takes place. 
Proposition 6 suggests that when presented with two policy instruments, namely to impose a tariff and to engage in an inter-governmental negotiation, the Home government will always choose the former. The intuition is straightforward. Imposing a tariff is costless to Home, for it can effectively shift profits one-way from Foreign to Home while reducing the Foreign output and increasing the Home output. However, negotiations with Foreign can be costly, as bargaining functions as a redistribution mechanism through which Home and Foreign divide the surplus (Home compensates Foreign for its loss by means of side payments). In other words, when given the possibility to choose to impose a tariff endogenously, Home prefers unilateral action to bilateral cooperation. Note also that the ability to use a tariff to shift profits from Foreign to Home also renders Home to value the F firm's profits, hence inducing it to choose mutual recognition.

\subsection{The case of Bertrand competition}

We proceed to consider the case where the policymakers endogenously determine the tariff rate and firms compete, à la Bertrand (denoted by superscript $T B$ ). Again, depending on the

firms' marginal costs, $c$ and $\delta e$, we have the following two subcases: (i) When $c \geq \delta e$, the F firm acquires the whole market (denoted by subscript $f$ ), and (ii) when $c<\delta e$, the $\mathrm{H}$ firm acquires the whole market (denoted by subscript $h$ ).

\subsubsection{The case where the F firm acquires the whole market}


When $c \geq \delta e$, both firms charge price $p_{f}^{T B}=c$ (the F-firm charges an $\varepsilon$ below $c$ to make sure that it has the whole market), with $q_{f}^{T B h}=0$ and $q_{f}^{T B f}=a-c$. Hence, the F firm's profits are $\pi_{f}^{T B f}=(c-\delta e)(a-c)$, whereas the $\mathrm{H}$ firm profits are $\pi_{f}^{T B h}=0$. The payoff to the Home government is given by

$$
G_{f}^{T B h} \equiv W_{f}^{T B h}+S_{f}^{T B}=C S_{f}^{T B h}+t q_{f}^{T B f}+\rho S_{f}^{T B}=(a-c)(a-c+2 t) / 2+S_{f}^{T B}
$$

Because $\partial G_{f}^{T B h} / \partial t_{f}^{T B}=a-c>0$, we see that the tariff rate is set equal to the $\mathrm{F}$ firm's markup, so that the $\mathrm{F}$ firm's entire profits are taken in the form of tariff income (i.e., $t_{f}^{T B}=c-\delta e$ ).

Because the F firm's contributions would be zero, the outcome of the bargaining would coincide with the choice of the Home government. The joint surplus is given by

$$
J S_{f}^{T B}=\Delta W_{f}^{T B h}+\Delta \pi_{f}^{T B f}=(a-c)(\delta-1) e .
$$

Because $\partial J S_{f}^{T B} / \partial \delta_{f}^{T B}=-(a-c) e<0$, we then note the following:

Proposition 7. When $c \geq \delta e$, and if bargaining occurs, the Home government chooses mutual recognition (i.e., $\delta^{T B *}=0$ ).

Proposition 7 resembles Proposition 4, suggesting that Proposition 4 holds under the case where the tariff is endogenously chosen. The underlying mechanism is similar: In the presence of bargaining, instead of only valuing domestic welfare, the Home government also values the profits of the F firm. 


\subsubsection{The case where the $\mathrm{H}$ firm acquires the whole market}

When $c<\delta e$, both firms charge price $p_{h}^{T B}=\delta e$ (again, the $\mathrm{H}$ firm charges an $\varepsilon$ below $\delta e$ to make sure that it has the whole market), with $q_{h}^{T B h}=a-\delta e$, and $q_{h}^{T B f}=0$. Hence, the $\mathrm{H}$

firm's profits are $\pi_{h}^{T B h}=(\delta e-c)(a-\delta e)$, whereas the $\mathrm{F}$ firm's profits are $\pi_{h}^{T B f}=0$. Clearly, because $\pi_{h}^{T B f}=0$, the Home government is indifferent towards choosing the tariff rate. The Home government' objective is given by

$$
G_{h}^{T B h} \equiv W_{h}^{T B h}+S_{h}^{T B}=\pi_{h}^{T B h}+C S_{h}^{T B h}=(\delta e-c)(a-\delta e)+(a-\delta e)^{2} / 2 .
$$

Because $\partial G_{h}^{T B h} / \partial \delta_{h}^{T B}=e(c-\delta e)>0$ and $\partial^{2} W_{h}^{T B h} / \partial\left(\delta_{h}^{T B}\right)^{2}=-e^{2}<0$, we see that the optimal $\delta_{h}^{T B *}=c / e<1$. Because $\pi_{h}^{B f}=0$, the F firm can only make a contribution of zero, indicating that the Home government shares the social planner's objective and will also set $\delta_{h}^{T B 0}=\delta_{h}^{T B *}=c / e$.

Proposition 8. When $c<\delta e$, the social planner and the Home government both set $\delta=c / e$.

Proposition 8 reiterates Proposition 5, exactly because the tariff rate is ineffective in the case of $c<\delta e$. Indeed, in such a case, the $\mathrm{H}$ firm has the whole market, whereas the export of the F firm to the Home market would be zero. 


\section{Conclusion}

It is commonly believed that harmonization among trading nations is a prerequisite for expanding trade, particularly in the context of trade between countries with different product standards, as, for example, repeatedly emphasized in the TPP and TTIP negotiations. However, we have shown that it is highly likely that mutual recognition of standards, and not the harmonization of standards, emerges as the Home's optimal choice as a result of trade negotiation, at least for the case of horizontally differentiated standards. We also demonstrate that mutual recognition can in fact maximize global welfare. Our findings thus throw doubt on the demands to reduce domestic diversity among trading nations, suggesting that these demands may in fact be ill-considered, and can hardly serve as a prediction of the outcomes of the international trade negotiations.

In our model, we have assumed that consumers cannot influence the setting of standards. One possible extension of the current work could be to consider the political interaction among the governments, firms, and consumers in the setting of standards, as in Swinnen (2015). Moreover, it might be of interest to compare our findings with the results derived from the models that consider vertically differentiated standards. 


\section{References}

Anderson JE, and Wincoop E. 2004. Trade costs. Journal of Economic Literature 42: $691-751$.

Baccini L, and Urpelainen J. 2012. Strategic side payments: Preferential trading agreements, economic reform, and foreign aid. Journal of Politics 74:932-949.

Barrett S. 2003. Environmental and statecraft: The strategy of environmental treaty-making. New York: Oxford University Press.

Cai D., and Li J. 2014. Protection versus free trade: Lobbying competition between domestic and foreign firms. Southern Economic Journal 81:489-505.

Chen N. 2004. Intra-national versus international trade in the European Union: Why do national borders matter? Journal of International Economics 63:93-118.

Chen MX, and Mattoo A. 2008. Regionalism in standards: Good or bad for trade? Canadian Journal of Economics 41:838-863.

Darby M, and Karni E. 1973. Free competition and the optimal amount of fraud. Journal of Law and Economics 16:67-88.

Edwards H, and Poyago-Theotoky J. 2013. Regulatory protection when firms decide first on technical collaboration and R\&D. Review of International Economics 21:750-764.

EU Commission. Test-case on functional equivalence: Proposed methodology for automotive regulatory equivalence. EU-US TTIP Negotiations Position Paper, January 7, 2015. Accessed December 2016. Available at http://trade.ec.europa.eu/doclib/docs/2015/january/tradoc_153023.pdf 
Felbermayr G.J., and Jung B. 2011. Sorting it out: Technical barriers to trade and industry productivity. Open Economic Review 22:93-117.

Grossman G.M., and Helpman E. 1994. Protection for sale. American Economic Review $84: 833-850$.

Lahiri S, and Ono Y. 2004. Trade and industrial policy under international oligopoly. Cambridge, UK: Cambridge University Press.

Jørgensen J.G., and Schröder, P.J.H. Harmonization versus Mutual Recognition: Some pitfalls for international coordination of product standards under imperfect competition, Discussion Paper on Business and Economics, 2015;23/2014; Department of Business and Economics, SDU.

Konishi H., Saggi K., and Weber S. 1999. Endogenous trade policy under foreign direct investment. Journal of International Economics 49:289-308.

Limao N., and Tovar P. 2011. Policy choice: Theory and evidence from commitment via international trade agreements. Journal of International Economics 85:186-205.

Maggi G., and Rodríguez-Clare A. 1998. The value of trade agreements in the presence of political pressures. Journal of Political Economy 106:574-601.

Nelson P. 1970. Information and consumer behavior. Journal of Political Economy 18: $103-123$.

Orefice G., and Roca N. 2014. Deep integration and production networks: An empirical analysis. The World Economy 37:106-136.

Orefice G., Piermartini R., and Rocha N. 2012. Harmonization and Mutual Recognition: What are the effects on trade? Mimeo; CEPII, Paris, France. 
Pelkmans J. 2015. TTIP: Challenges \& opportunities for IMCO in TBT matters, European Parliament, IMCO/INTA, 2015; 24 February 2015, Brussels.

Pelkmans J. 2012. Mutual recognition: Economic and regulatory logic in goods and services, Bruges European Economic Research Papers, 24/2012.

Stoyanov A. 2009. Trade policy of a free trade agreement in the presence of foreign lobbying. Journal of International Economics 77:37-49.

Sturm D.M. 2006. Product standards, trade disputes, and protectionism. Canadian Journal of Economics 39: 564-581.

Swinnen J., Deconinck K., Vandemoortele T., and Vandeplas A. 2015. Quality standards, value chains, and international development. New York: Cambridge University Press.

Togan A. 2015. Technical barriers to trade: The case of Turkey and the European Union, Journal of Economic Integration 30:121-147.

World Trade Organization (WTO). 2005. World trade report 2005: Trade, Standards and the WTO, Geneva: World Trade Organization.

World Trade Organization (WTO). 2012. World trade report 2012: Trade and public policies: A closer look at non-tariff measures in the $21^{\text {st }}$ century. Geneva: World Trade Organization. 


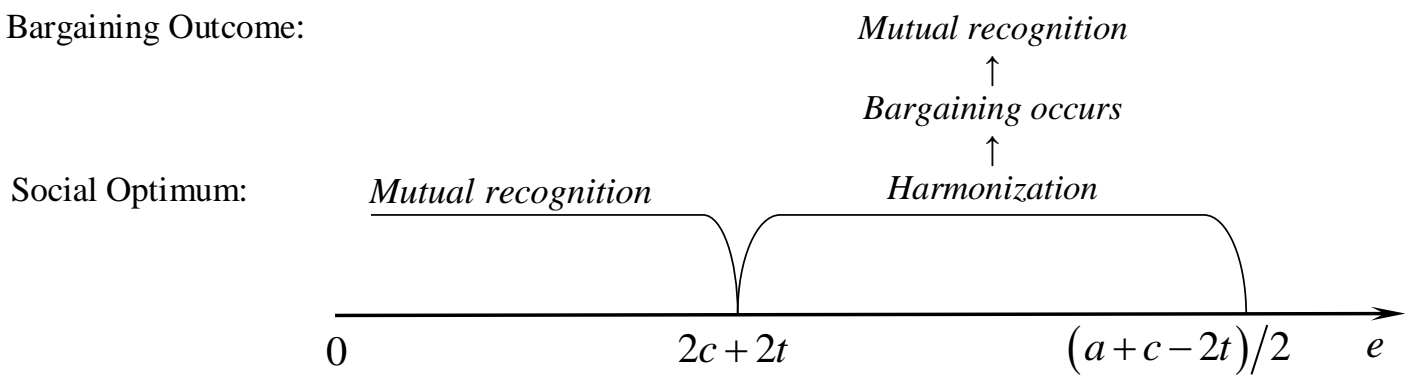

Figure 1. Social optimum versus the bargaining outcome 